\title{
A novel compound heterozygous variant in CYP19A1 resulting in aromatase deficiency with normal ovarian tissue
}

\author{
Sezer Acar ${ }^{1 \oplus}$, İbrahim Mert Erbaş ${ }^{1 \oplus}$, Ahu Paketçi ${ }^{1 \oplus}$, Hüseyin Onay ${ }^{2 \oplus}$, \\ Tufan Çankaya ${ }^{3 \oplus}$, Semra Gürsoy ${ }^{4 \oplus}$, Bayram Özhan ${ }^{5 \oplus}$, Ayhan Abac1 ${ }^{1 \oplus}$, \\ Erdener Özer ${ }^{6 \oplus}$, Mustafa Olguner $^{7 \oplus}$, Ece Böber ${ }^{1 \oplus}$, Korcan Demir $^{1 \oplus}$ \\ Departments of ${ }^{1}$ Pediatric Endocrinology, ${ }^{3}$ Medical Genetics, ${ }^{4}$ Pediatric Genetics, ${ }^{6}$ Pathology and ${ }^{7}$ Pediatric Surgery, Dokuz Eylül \\ University Faculty of Medicine, Izmir; ${ }^{2}$ Department of Medical Genetics, Ege University Faculty of Medicine, Izmir; ${ }^{5}$ Department of \\ Pediatric Endocrinology, Pamukkale University Faculty of Medicine, Denizli, Turkey.
}

\begin{abstract}
Background. Aromatase deficiency leading to virilization in mother and female fetuses during pregnancy is a rare disease. It is characterized by impaired estrogen production, increased gonadotropins, and ovarian cysts.

Case. Herein, we report a clinical phenotype of the virilized female due to a novel compound heterozygous variant in CYP19A1 [IVS10 + 1 G> A; c.344 G> A (p.R115Q)], with normal gonadotropin levels at the time of admission and histologically normal ovarian tissues.
\end{abstract}

Conclusion. Aromatase deficiency should also be considered even if the initial follicle-stimulating hormone (FSH) and luteinizing hormone (LH) levels are normal, and ovarian cysts are lacking.

Key words: disorders of sex development, p450 oxidoreductase deficiency, clitoromegaly, hirsutism, ambiguous genitalia.

Aromatase is a type II cytochrome P450 enzyme located in the endoplasmic reticulum, which catalyzes the conversion of C19 steroids (testosterone, 16-alpha-hydroxytestosterone, and androstenedione) into C18 steroids (17 beta-estradiol, estriol, and estrone). It is encoded by the CYP19A1 gene located on chromosome $15 \mathrm{q} 21.1{ }^{1}$ Aromatase deficiency is a rare autosomal recessive disorder that leads to increased androgen levels in both the fetus and the mother. The latter condition results in specific signs of maternal virilization including cystic acne, hirsutism, clitoromegaly, and deep voice. $^{2}$

$凶$ Korcan Demir

korcan.demir@deu.edu.tr

Received 27th August 2019, revised 7th May 2020, accepted 21st May 2020.
It was first described by Shozu et al. ${ }^{3}$ in 1991. Subsequent experimental studies showed that aromatase-knockout female mice developed a male body habitus, had small or polycystic ovaries with no corpora lutei, small uteri, and they were infertile. ${ }^{4}$ Until now, nearly 40 cases with varying clinical presentations from various ethnic groups were reported.

Female cases with aromatase deficiency have ambiguous genitalia at birth, failure to enter puberty, a propensity to develop ovarian cysts, increased gonadotropins and pronounced virilization. ${ }^{1}$ During childhood, both serum basal or gonadotropin-releasing hormone $(\mathrm{GnRH})$ induced follicle stimulating hormone (FSH) and luteinizing hormone (LH) levels are expected to be elevated. Thereby, high concentrations of circulating gonadotropins and increased intraovarian androgen levels usually cause large and polycystic ovaries from the infancy period. ${ }^{1}$ 
Herein, we report a virilized female infant with normal ovarian morphology and initially normal gonadotropin levels associated with a novel compound heterozygous variant [IVS10 + 1 G>A; p.R115Q (c.344 G>A)] in CYP19A1.

\section{Case Report}

A 4-month-old girl was referred to our outpatient clinic due to clitoromegaly, which was decreasing in size since birth. She was born with a birth weight of 2710 grams at $35^{\text {th }}$ week of gestation. Her parents were unrelated. Her mother had developed acne, hair loss, voice change, and hirsutism during pregnancy. There was no similar case in family history.

Physical examination revealed normal weight [6.8 kg; 0.4 standard deviation score (SDS), 50-75p] and length (64 cm; 0.5 SDS, 50-75p). Clitoris was $1 \mathrm{~cm}$ long and labia minora were fused posteriorly. There were no gonad-like structures in the inguinal region. The remaining systemic examination was normal.

A number of laboratory tests already performed before admission to our unit were interpreted as normal [16th day of life, adrenocorticotropic hormone $29.6 \mathrm{pg} / \mathrm{ml}(0-46)$, cortisol $1.57 \mu \mathrm{g} / \mathrm{dl}$ $(0.55-19.8 \mu \mathrm{g} / \mathrm{dl}), 17-\mathrm{OH}$ progesterone $9.89 \mathrm{ng} /$ $\mathrm{ml}(<20 \mathrm{ng} / \mathrm{ml})$, androstenedione $1.15 \mathrm{ng} / \mathrm{ml}$ (0.3-3.3 ng/ml), anti-Mullerian hormone 0.04 $\mathrm{ng} / \mathrm{ml}$ ( $<4.7 \mathrm{ng} / \mathrm{ml}$ for females)]. Gonadotropin levels were normal at the time of admission (Table I). Ultrasonography revealed a normal uterus and but no ovarian tissue, confirming previous findings. Karyotype was identified as 46,XX. Fluorescence in situ hybridization (FISH) analysis demonstrated no $\mathrm{Y}$ chromosome among 200 nuclei. The testis-determining gene
$(S R Y)$ was not detected via the polymerase chain reaction (PCR). At $6^{\text {th }}$ month of age, vaginoscopy and laparoscopy were performed in order to plan surgery and vagen, uterus, and ovaries were considered normal. In addition, gonadal biopsies were performed during the laparoscopy due to investigate the gonadal karyotype and for differential diagnosis of ovotesticular syndrome. The biopsy specimens from both gonads were histologically consistent with normal ovarian tissue (Fig. 1). The karyotype analyses of those specimens revealed $46, \mathrm{XX}$ in both gonads.

The diagnosis of aromatase deficiency was considered according to these findings. Cytochrome p450 oxidoreductase deficiency can also be thought in similar circumstances, however, normal 17-OH progesterone levels are uncommon in this situation. Genetic analysis of the case revealed a compound heterozygous variant in CYP19A1 [novel IVS10 + 1 G> A; novel p.R115Q (c.344 G> A)] (Fig. 2). In silico analyzes categorized the variants to be pathogenic. The mother and the father were heterozygous

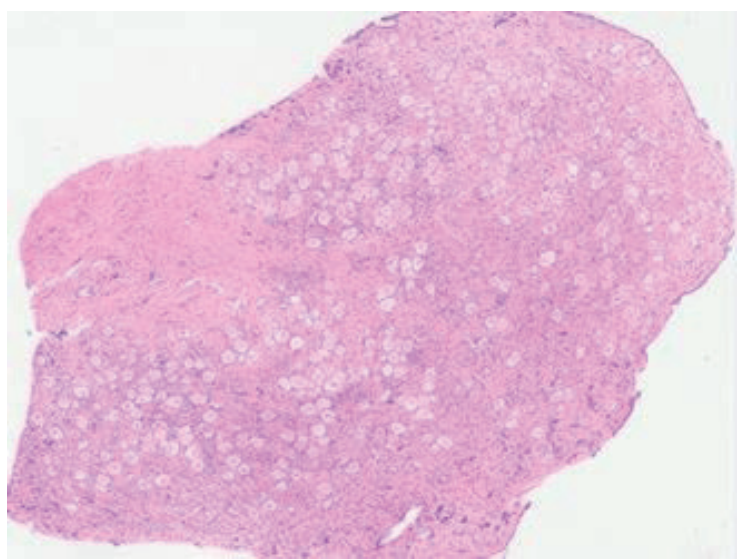

Fig. 1. Normal ovarian tissue histology from the biopsy specimens of both gonads.

Table I. Hormone levels of the case at different time points.

\begin{tabular}{lcccccc}
\hline & $16^{\text {th }}$ day & $4^{\text {th }}$ month & $6^{\text {th }}$ month & $8^{\text {th }}$ month & $1^{\text {th }}$ month & $17^{\text {th }}$ month \\
\hline FSH $(\mathrm{mIU} / \mathrm{ml})$ & 6.4 & 7.02 & 36.3 & 18.7 & 27.9 & 75.1 \\
LH $(\mathrm{mIU} / \mathrm{ml})$ & 0.53 & 0.97 & 4.36 & 1.27 & 0.77 & 15.64 \\
Estradiol $(\mathrm{pg} / \mathrm{ml})$ & 5.0 & $<20$ & $<20$ & $<20$ & $<20$ & $<20$ \\
Total testosterone $(\mathrm{ng} / \mathrm{dl})$ & 78 & $<10$ & $<10$ & - & - & - \\
\hline
\end{tabular}

FSH: follicle-stimulating hormone, LH: luteinizing hormone. 


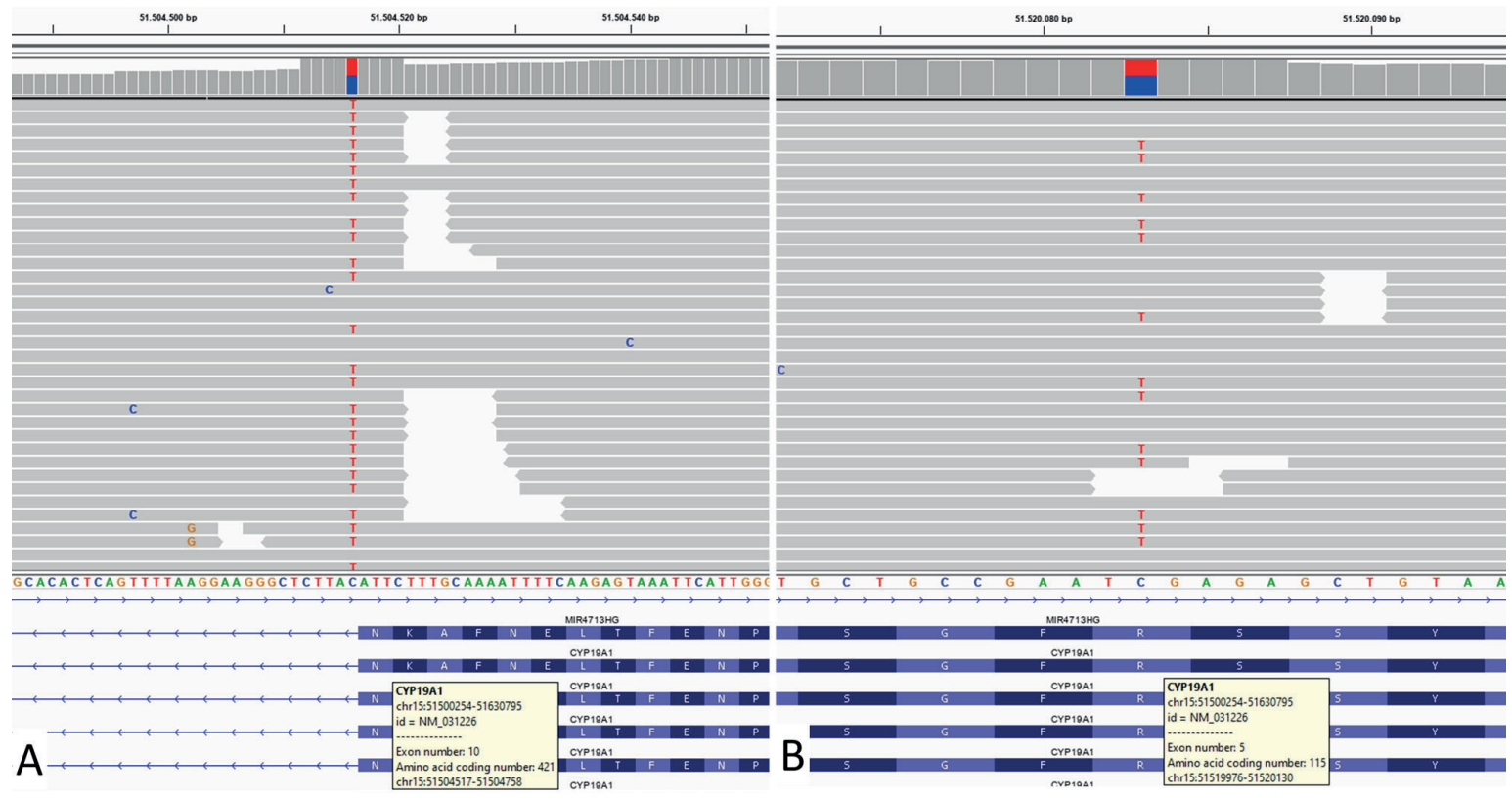

Fig. 2. Partial sequences of CYP19A1 of the patient demonstrating (a) heterozygous IVS10 + 1 G> A, (b) heterozygous c.344 G> A.

carriers of p.R115Q (c.344 G>A) and IVS10 + 1 $\mathrm{G}>\mathrm{A}$ variant, respectively.

During the follow-up, the fusion at the posterior of the labium minus was surgically corrected. No ovarian cyst was observed with pelvic ultrasonography until the last visit at the age of 3 years. Her weight was $17.2 \mathrm{~kg}$ (1.6 SDS, 8595p), and height was $100 \mathrm{~cm}$ (0.9 SDS, 75-85p) on the last visit (BMI $17.5 \mathrm{~kg} / \mathrm{m}^{2}, 1.19$ SDS, 8595p). Written informed consent was obtained from the parents for publication of the case.

\section{Discussion}

Aromatase deficiency is a rare disease characterized by a decrement in estrogen synthesis, due to reduced aromatase activity. Until today, more than 32 variants in the CYP19A1 gene, including missense, nonsense, small deletions and insertions, splice site variants, and one large intragenic deletion, have been described in patients with aromatase deficiency. ${ }^{1,5-8}$ The majority of variants were missense and located in exons 9 and 10, which encode the substrate (androgen)-binding site and haem-binding domains, respectively. ${ }^{5}$ In the current study, we identified a novel compound heterozygous variant in CYP19A1 [IVS10 + 1 G> A; p.R115Q (c.344 G> A)]. In contrast to the previous cases reported from our country, the locations of variants detected in our case were different..$^{6-8}$ The missense variant (c.344 G> A) is localized in exon 4 and IVS10 $+1 \mathrm{G}>\mathrm{A}$ is a splice site defect localized in $10^{\text {th }}$ intron of the CYP19A1.

Due to placental aromatase deficiency, the conversion of androgen into estrogen decreases, and therefore high levels of androgen circulates in maternal blood. ${ }^{2}$ The mother with a fetus, who has aromatase deficiency, develops progressive virilization symptoms during pregnancy such as an increase in acne, voice thickening, clitoromegaly, frontal baldness, and facial hirsutism. These findings in the mother regress after birth. ${ }^{2,9,10}$ Similarly, the mother of our patient developed virilization symptoms, including acne, hair loss, voice change, and hirsutism during pregnancy.

Aromatase deficiency results in varying degrees of virilization in the external genitalia in newborn girls due to high intrauterine androgen concentration. Gonads are non-palpable and 
female internal genitalia differentiation was not affected. On the other hand, there is no change in the external genitalia in boys at birth. All infants born full-term with adequate weight for gestational age. ${ }^{1,311,12}$ The birthweight of our patient was normal for gestational age (2710 grams at 35th gestational week). She had clitoromegaly, posterior labia minora fusion, and but normal uterus and ovaries.

In female cases with aromatase deficiency, changes in the hypothalamic-pituitary-gonadal axiscause someclinicalissues. During childhood, both serum basal and GnRH-induced FSH-LH levels are expected to be elevated, starting from $2^{\text {nd }}$ month of age. ${ }^{1}$ However, the estradiol and estrone levels tend to be remarkably low during this same period. ${ }^{9,11}$ In our case, gonadotropin levels were normal at the time of admission but started to increase by the age of 6 months. Excessive virilization and lack of the start of puberty are expected in affected females, with primary amenorrhea and also absence of breast development. The pubertal spurt is lacking and bone age delayed.10-12 Increased intra-ovarian androgen levels and high concentrations of circulating gonadotropins usually cause large and polycystic ovaries from the infancy period. ${ }^{1}$ However, in a total of six cases from four studies, hypoplastic or non-cystic ovaries have been reported. Gagliardi et al. ${ }^{5}$ reported streak ovaries in a case and commented that it was due to estrogen treatment before the diagnosis. Lin et al. ${ }^{10}$ reported a case with streak ovaries and suggested that the streak ovaries may be a constitutional presentation of CYP19A1 deficiency. Other patients from two reports (age, 19 months-7 years of age) had not received estrogen treatment, and no cystic structure was noted. 6,7 When the laparoscopy was required for our patient, it was considered to take a sample from the ovary in terms of the possibility of ovotestis. ${ }^{13}$ Although a normal gonadal appearance was seen, this would not always indicate a normal histology as a demarcation line was not remarkable in some patients with ovotestis described in literature. ${ }^{14}$ Unlikely to most of the patients with aromatase deficiency, the biopsy specimens from both gonads of the present case were histologically consistent with normal ovarian tissue, and no cystic structure developed during the follow-up. Thinking retrospectively, we would not need to perform an ovarian biopsy if a genetic diagnosis could be made earlier.

Treatment in aromatase deficiency consists of estrogen replacement in girls; however, there is no concurrence on the dosage or age of beginning. Estrogen treatment normalizes bone maturation, gonadotropin secretion with a feedback mechanism. ${ }^{9,15,16}$ It is also useful for glucose and insulin metabolism and decreases lipid levels., ${ }^{916}$ We have not started estrogen replacement yet, as our case did not have any ovarian cysts or metabolic syndrome.

In conclusion, we presented a case with aromatase deficiency caused by a novel variant in the CYP19A1 gene. Aromatase deficiency should be considered in children with ambiguous genitalia who have a history of maternal virilization during pregnancy and karyotype of 46,XX, even if the initial FSH and LH levels are normal and ovarian cysts are lacking.

\section{REFERENCES}

1. Belgorosky A, Guercio G, Pepe C, Saraco N, Rivarola MA. Genetic and clinical spectrum of aromatase deficiency in infancy, childhood and adolescence. Horm Res 2009; 72: 321-330.

2. Bulun SE. Aromatase and estrogen receptor $\alpha$ deficiency. Fertil Steril 2014; 101: 323-329.

3. Shozu M, Akasofu K, Harada T, Kubota Y. A new cause of female pseudohermaphroditism: placental aromatase deficiency. J Clin Endocrinol Metab 1991; 72: 560-566.

4. Fisher CR, Graves KH, Parlow AF, Simpson ER. Characterization of mice deficient in aromatase (ArKO) because of targeted disruption of the cyp19 gene. Proc Natl Acad Sci USA 1998; 95: 6965-6970.

5. Gagliardi L, Scott HS, Feng J, Torpy DJ. A case of aromatase deficiency due to a novel CYP19A1 mutation. BMC Endocr Disord 2014; 14: 16. 
6. Akçurin S, Türkkahraman D, Kim WY, Durmaz E, Shin JG, Lee SJ. A novel null mutation in P450 aromatase gene (CYP19A1) associated with development of hypoplastic ovaries in Humans. J Clin Res Pediatr Endocrinol 2016; 8: 205-210.

7. Unal E, Yıldırım R, Taş FF, Demir V, Onay H, Haspolat YK. Aromatase deficiency due to a novel mutation in CYP19A1 gene. J Clin Res Pediatr Endocrinol 2018; 10: 377-381.

8. Ozen S, Atik T, Korkmaz O, et al. Aromatase deficiency in two siblings with 46, XX karyotype raised as different genders: a novel mutation (p.R115X) in CYP19A1 gene. J Clin Res Pediatr Endocrinol 2020; 12: 109-112.

9. Belgorosky A, Pepe C, Marino R, et al. Hypothalamicpituitary-ovarian axis during infancy, early and late prepuberty in an aromatase-deficient girl who is a compound heterocygote for two new point mutations of the CYP19 gene. J Clin Endocrinol Metab 2003; 88: 5127-5131.

10. Lin L, Ercan O, Raza J, et al. Variable phenotypes associated with aromatase (CYP19) insufficiency in humans. J Clin Endocrinol Metab 2007; 92: 982-990.

11. Conte FA, Grumbach MM, Ito Y, Fisher CR, Simpson ER. A syndrome of female pseudohermaphrodism, hypergonadotropic hypogonadism, and multicystic ovaries associated with missense mutations in the gene encoding aromatase (P450arom). J Clin Endocrinol Metab 1994; 78: 1287-1292.
12. Morishima A, Grumbach MM, Simpson ER, Fisher C, Qin K. Aromatase deficiency in male and female siblings caused by a novel mutation and the physiological role of estrogens. J Clin Endocrinol Metab 1995; 80: 3689-3698.

13. León NY, Reyes AP, Harley VR. A clinical algorithm to diagnose differences of sex development. Lancet Diabetes Endocrinol 2019; 7: 560-574.

14. Mao Y, Chen S, Wang R, Wang X, Qin D, Tang Y. Evaluation and treatment for ovotesticular disorder of sex development (OT-DSD) - experience based on a Chinese series. BMC Urol 2017; 17: 21.

15. Rochira V, Balestrieri A, Madeo B, Spaggiari A, Carani C. Congenital estrogen deficiency in men: a new syndrome with different phenotypes; clinical and therapeutic implications in men. Mol Cell Endocrinol 2002; 193: 19-28.

16. Maffei L, Murata Y, Rochira V, et al. Dysmetabolic syndrome in a man with a novel mutation of the aromatase gene: effects of testosterone, alendronate, and estradiol treatment. J Clin Endocrinol Metab 2004; 89: 61-70. 